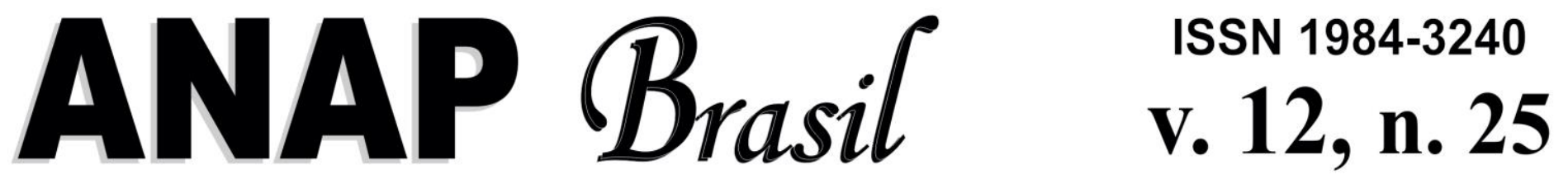

REVISTA CIENTÍFICA 2019

\title{
A Paisagem de Vila Velha: o desafio da conservação do patrimônio cultural/natural da APA de Santa Cruz, Itamaracá (PE)
}

The Landscape Of Vila Velha: the challenge of conservation of the cultural / natural heritage of the APA of Santa Cruz, in Itamaracá (PE)

El Paisaje De Vila Velha: el desafío de La conservación Del patrimonio cultural / natural de la APA de Santa Cruz, Itamaracá (PE)

\author{
Pedro Henrique Valença Ferreira \\ Graduando em Arquitetura e Urbanismo, UFPE, Brasil. \\ pedro.valenca.ferreira@gmail.com \\ Jônatas Souza Medeiros da Silva \\ Mestrando em Desenvolvimento Urbano, UFPE, Brasil. \\ jona.medeiros@gmail.com \\ Onilda Gomes Bezerra \\ onibezerra@yahoo.com.br
} Professora Doutora do Departamento de Arquitetura e Urbanismo, UFPE, Brasil. 


\section{RESUMO}

O presente trabalho tem como objetivo compreender a paisagem de Vila Velha, situada no município da Ilha de Itamaracá, Pernambuco, onde ainda hoje se descobrem sítios arqueológicos que datam desde a colonização da costa brasileira, no século XVI. O povoado de Vila Velha é tombado em instância estadual pela Fundação do Patrimônio Histórico e Artístico de Pernambuco (FUNDARPE), e compreende-se dentro dos limites da APA de Santa Cruz, Unidade de Conservação da Natureza do Estado de Pernambuco, daí serem analisados de forma conjunta. Neste artigo, busca-se entender como se encontra o povoado de Vila Velha quanto a sua conservação, já que se insere numa sobreposição de proteção institucioanal em dois campos distintos do patrimônio, de modo a buscar soluções para enfrentar o desafio que é a conservação integrada do patrimônio cultural e natural. Objetiva-se ainda caracterizar seus atributos patrimoniais, que contribuem para a fundamentação do processo de reconhecimento oficial desse patrimônio natural e cultural. Como resultado, tem-se o conhecimento patrimonial do bem que, consequentemente, serve para embasar a construção de instrumentos operacionais voltados à gestão da conservação integrada do sítio.

PALAVRAS-CHAVE: Conservação da Natureza. Patrimônio Cultural/Natural. Gestão da Conservação.

\section{ABSTRACT}

The present work aims to understand the landscape of Vila Velha, located in the municipality of Itamaracá Island, Pernambuco, where archaeological sites dating to the 16th century are still to be found. The town of Vila Velha is registered in a state instance by the Pernambuco Foundation for Historical and Artistic Heritage (FUNDARPE), and is comprised within the limits of the APA of Santa Cruz, Pernambuco State Nature Conservation Unit together. In this article, we try to understand how the village of Vila Velha is located in terms of its conservation, since it is inserted in an overlap of institutional protection in two distinct areas of heritage, in order to find solutions to face the challenge of integrated conservation cultural and natural heritage. It also aims to characterize its patrimonial attributes, which contribute to the foundation of the process of official recognition of this natural and cultural patrimony. As a result, we have the patrimonial knowledge of the good that, consequently, serves to base the construction of operational instruments aimed at the integrated conservation management of the site.

KEY WORDS: Nature Conservation. Cultural / Natural Heritage. Conservation Management.

\section{RESUMEN}

El presente trabajo tiene como objetivo comprender el paisaje de Vila Velha, situada en el municipio de la Isla de Itamaracá, Pernambuco, donde aún hoy se descubren sitios arqueológicos que datan desde la colonización de la costa brasileña, en el siglo XVI. El pueblo de Vila Velha es tumbado en instancia estatal por la Fundación del Patrimonio Histórico y Artístico de Pernambuco (FUNDARPE), y se comprende dentro de los límites de la APA de Santa Cruz, Unidad de Conservación de la Naturaleza del Estado de Pernambuco, de ahí analizarse forma conjunta. En este artículo, se busca entender cómo se encuentra el pueblo de Vila Velha en cuanto a su conservación, ya que se inserta en una superposición de protección institucional en dos campos distintos del patrimonio, para buscar soluciones para enfrentar el desafío que es la conservación integrada del patrimonio cultural y natural. Se pretende además caracterizar sus atributos patrimoniales, que contribuyen a la fundamentación del proceso de reconocimiento oficial de ese patrimonio natural y cultural. Como resultado, se tiene el conocimiento patrimonial del bien que, en consecuencia, sirve para basar la construcción de instrumentos operacionales dirigidos a la gestión de la conservación integrada del sitio.

PALABRAS CLAVE: Conservación de la Naturaleza. Patrimonio Cultural / Natural. Gestión de la Conservación. 


\section{ANAP \\ Brasil \\ ISSN 1984-3240 v. 12, n. 25}

\section{R E V IS T A}

No campo da conservação encontram-se duas grandes áreas distintas do patrimônio reconhecidas através de suas características: uma que traz seu caráter cultural e outra o caráter natural. Muitos bens patrimoniais apresentam características que agregam a si parte desses dois campos do patrimônio. Entretanto, no processo de reconhecimento não é possível abrangê-lo por completo, pelo fato destas duas dimensões patrimoniais serem tratadas e analisadas de modo distinto, causando uma salvaguarda parcial do bem.

Nas últimas décadas, com o avanço dos estudos acerca do patrimônio natural, tem-se percebido com maior clareza essa dissociabilidade do caráter cultural no seu processo de conservação. A Recomendação de Paris de 1972 é um exemplo deste tratamento dicotômico dos dois campos. Esta carta patrimonial foi o primeiro documento oficial que retratou as duas dimensões patrimoniais, cultural e natural, em um único documento, revelando sua a significativa importância do bem patrimonial para os povos, pelo interesse e reconhecimento do seu valor universal excepcional. Mesmo lançando orientações pertinentes ao patrimônio cultural e natural, com o intuito de conservar, proteger e preservar esses bens tão significativos para o planeta, não apenas pelo seu caráter ecossistêmico, mas como caráter intrínseco à cultura humana, institucionaliza a salvaguarda como dois processos de preservação distintos.

Atualmente, por compreender que o ser humano é o responsável pela valoração de todo e qualquer bem, através de sua percepção sobre ele, há o entendimento da necessidade de salvaguardá-lo, mesmo indiretamente, uma vez que a cultura se imbrica ao patrimônio natural como parte intrínseca. Desse modo, é necessário desenvolver um processo de salvaguarda que integre estes dois campos patrimoniais, de modo que a preservação seja plena e que os valores se apresentam simultaneamente nestes dois âmbitos.

A proteção e salvaguarda numa perspectiva integrada das duas dimensões patrimoniais é apresentada na Carta do Patrimônio Natural da Austrália quando traz à tona que "os locais podem ter valores patrimoniais naturais e culturais. Esses valores podem estar relacionados $\mathrm{e}$ às vezes são difíceis de separar" (AUSTRALIAN NATURAL HERITAGE CHARTER, 2002, p. 4, tradução nossa). Com isso, entende-se que os atributos e naturais e culturais estão associados e no fim formam uma unidade que deve ser preservada de forma conjunta.

Nesse sentido, observa-se que os atuais estudos da paisagem sinalizam para um conteúdo que envolve a totalidade das dimensões naturais e culturais, simultaneamente. Há que ressaltar, portanto, a ampliação dos aspectos naturais, incorporando o teor sócio-histórico e cultural do sítio onde esses se inserem. Conforme pontua Ab'Saber (2003), a paisagem é uma "herança de processos fisiográficos e biológicos", portanto "patrimônio coletivo dos povos que historicamente as herdaram como território de atuação de suas comunidades" (AB'SÁBER, 2003). A Carta Europeia da Paisagem (2000, art. 19), por outro lado, corrobora com essa ideia ao definir a paisagem como "parte do território, tal como é apreendida pelas populações, cujo caráter resulta da ação e da interação de fatores naturais e ou humanos". Berque (2010, p.10) também ressalta que os territórios não são neutros e que os seres humanos se confundem 


\section{ANAP Brasil

\section{REVISTA CIENTÍFICA}

com a paisagem, não fisicamente, mas "na relação que os habitantes estabelecem com o território, não na substância enquanto objeto".

Materializando essa problemática, levanta-se como objeto de estudo para a presente investigação a Área de Preservação Ambiental (APA) de Santa Cruz, Unidade de Conservação da natureza estadual, delimitada pelo Decreto no 32.488/2008, que ocupa toda a área do município de Itapissuma e Itamaracá, além de parte do município de Goiana, cidades situadas na zona norte da Região Metropolitana do Recife (PE), (figura 1). Esta unidade protegida possui uma importância sublime para os estudos de biodiversidade da área litorânea não apenas do estado de Pernambuco, mas do Nordeste, revelando grande parte da riqueza de ecossistemas associados que ainda resistem e devem ser preservados.

Figura 1: Mapa de localização da APA de Santa Cruz

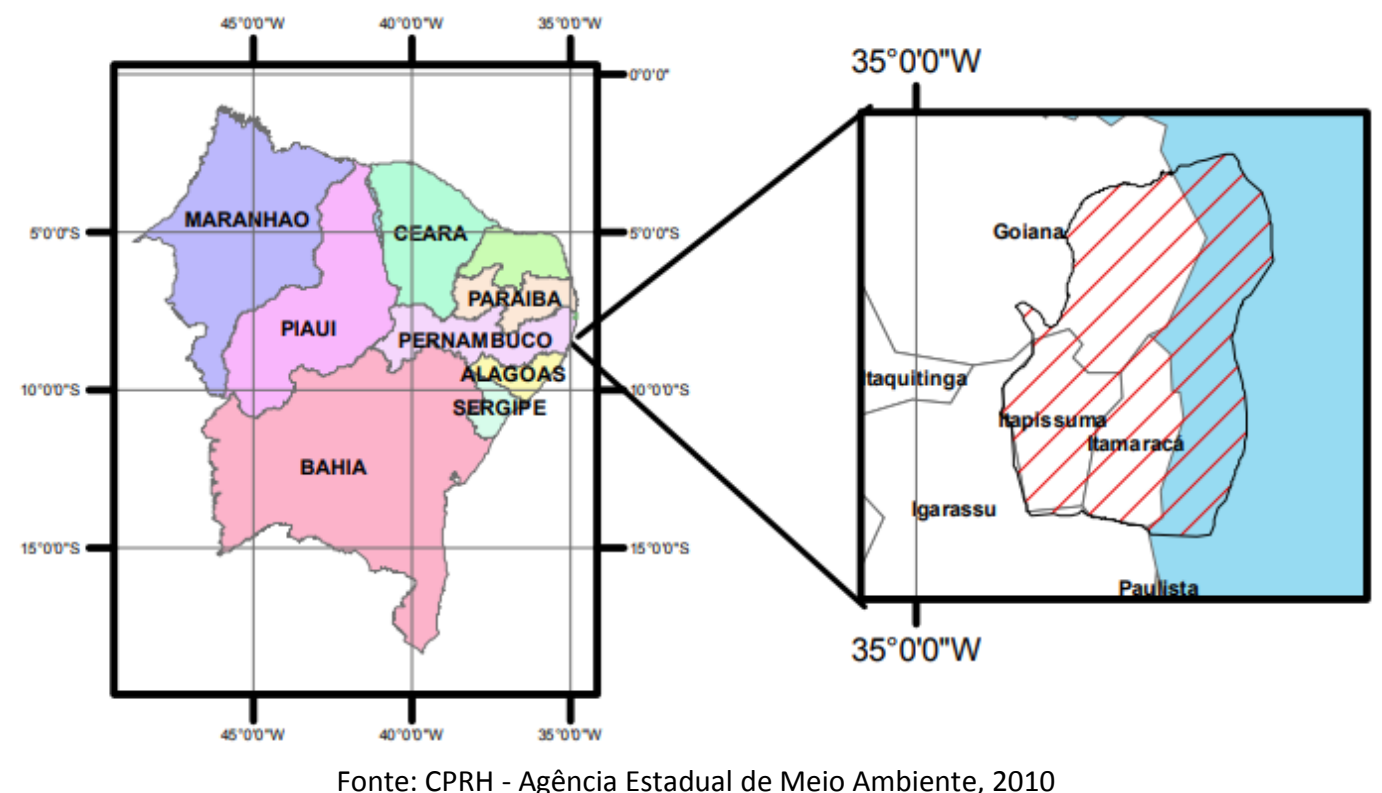

Dentro dessa unidade protegida, existe o conjunto histórico e entorno que compõem o povoado de Vila Velha, localizado na Ilha de Itamaracá (PE), (figura 2). Esse sítio, tombado em instância estadual pela Fundação do Patrimônio Histórico e Artístico de Pernambuco (FUNDARPE) - Processo no 004748/1994, conserva resquícios do período histórico da ocupação brasileira, sendo um dos primeiros pontos no Brasil colônia em que foi estabelecida uma feitoria. 


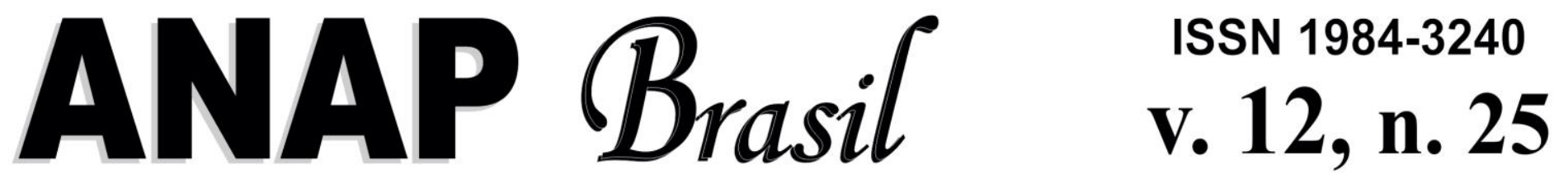

REVISTA CIENTÍFICA 2019

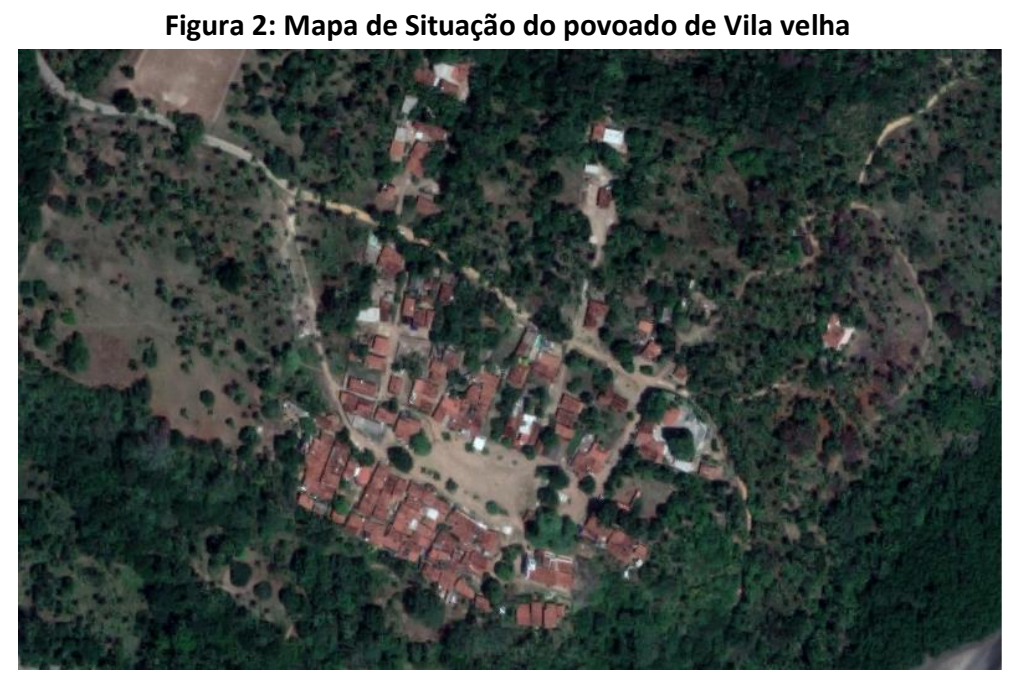

Fonte: GOOGLE MAPS - Imagem de satélite, 2019

Todavia, há visíveis disfunções na coordenação do processo de uma gestão para a sua conservação. A falta de instrumentos operacionais para uma gestão integrada desse patrimônio, onde se entrelaçam, as dimensões naturais e culturais que são trabalhadas individualmente promove danos às próprias ações de proteção o que evidencia o desafio que é o processo de sua salvaguarda.

Assim, pretende-se discutir neste artigo o estado em que se encontra o povoado de Vila Velha levando-se em conta o processo de conservação vigente, já que abarca uma sobreposição nos mecanismos de proteção de dois campos distintos do patrimônio. a Nesse sentido, almeja-se buscar soluções para enfrentar o grande desafio que é a conservação integrada do patrimônio cultural e natural.

\section{OBJETIVOS}

Em consonância com o problema levantado, o estudo aqui apresentado tem como objetivo analisar a situação atual da paisagem de Vila Velha a partir da compreensão do seu estado de conservação tanto em suas dimensões histórico-culturais quanto naturais, dada a sua importância como elemento crucial no reconhecimento do povoado enquanto um bem patrimonial cultural e natural.

Este artigo trata da primeira etapa da pesquisa intitulada "A PAISAGEM DE VILA VELHA: instrumentos para a gestão da conservação do patrimônio cultural/natural da APA de Santa Cruz, Itamaracá (PE)" desenvolvida no grupo de pesquisa Conservação do Patrimônio Natural, vinculado ao Laboratório da Paisagem/UFPE. Com ela pretende-se identificar os seus valores culturais e naturais visando contribuir na fundamentação do processo de reconhecimento oficial do patrimônio natural e cultural, de modo a apontar diretrizes operacionais para uma gestão da conservação integrada desse conjunto patrimonial. 


\section{REVISTA C I E}

Os procedimentos metodológicos adotados para análise e interpretação da situação atual da paisagem de Vila Velha, compreendendo-a como um bem único onde há integração do patrimônio cultural e natural, operacionalizam-se mediante um levantamento de informações acerca do objeto de estudo visando à caracterização de seus atributos e a identificação dos valores patrimoniais do bem.

Para consecução da pesquisa desenvolve-se a seguinte estruturação metodológica para sua realização:

1. Compreensão do bem: Busca-se aqui a caracterização do objeto de estudo a partir de um levantamento de dados relativos aos aspectos da história do lugar e institucional, buscando informações que confirme a sua condição de patrimônio natural e cultural. Para o cumprimento desta etapa, foram consultados acervos, como jornais, mapas, plantas, registros fotográficos e documentações oficiais, instrumentos normativos e demais informações técnico-científicas sobre o lugar.

2. Análise da situação atual: Corresponde a identificação do estado atual de conservação do sítio estudado. Nesta etapa, contou-se com visitas in loco, para levantamento fotográfico, estudo físico-territorial e florístico da área, como também, consultas a gestores e especialistas mediante aplicação de entrevistas semi-estruturadas.

3. Definição de ações de conservação: Visando identificar a relação que as pessoas têm com o conjunto patrimonial e o nível de comprometimento quanto às ações a serem empreendidas para sua proteção, foram ouvidas algumas pessoas-chave que mantivessem estreito envolvimento com o bem e pudesse exercer importante papel no processo de gestão. Foram aplicadas entrevistas, cujas falas foram analisadas por meio do método de análise de conteúdo. Os grupos entrevistados foram especialistas da área patrimonial, bem como os moradores locais, a fim de se avaliar o estado de conservação da paisagem de Vila Velha, de modo a compreender o papel de cada um no processo de gestão.

\section{RESULTADOS}

As informações obtidas sobre o povoado de Vila Velha, localizado na llha de Itamaracá, atestam que a área é um sítio geográfico bastante significativo pelo conjunto de valores que ali se expressam, tanto históricos, por ser um dos pontos iniciais da colonização portuguesa no Estado, quanto naturais, por estar inserida em uma Unidade Protegida - APA de Santa Cruz.

De acordo com a Agência Estadual de Meio Ambiente (CPRH), a referida unidade de conservação da natureza possui uma área total de 38.692ha, sendo 24.943ha de área continental e 13.749ha de área marítima. Trata-se de um conjunto de ecossistemas associados, que inclui bancos de arenito, arrecifes de corais, áreas destinadas à aquicultura, manguezais e outras áreas estuarinas, remanescentes de Mata Atlântica e refúgios de vida 


\section{ANAP

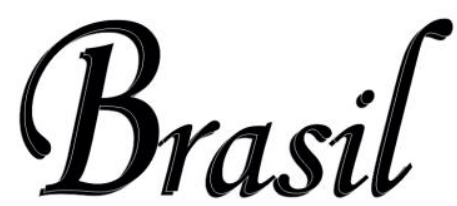 \\ ISSN 1984-3240 \\ V. 12, n. 25}

\section{REVISTA CIENTÍFICA 2019}

silvestre, (figura 3). Está classificada pelo Atlas da Biodiversidade de Pernambuco (PERNAMBUCO, 2002), em diversas categorias de fauna e flora, como uma área de extrema importância para a conservação da natureza dada a sua relevante biodiversidade. Representa assim, uma unidade ecológica de excepcional significado ambiental e socioeconômico para Pernambuco.

Figura 3: Patrimônio Natural do povoado de Vila Velha

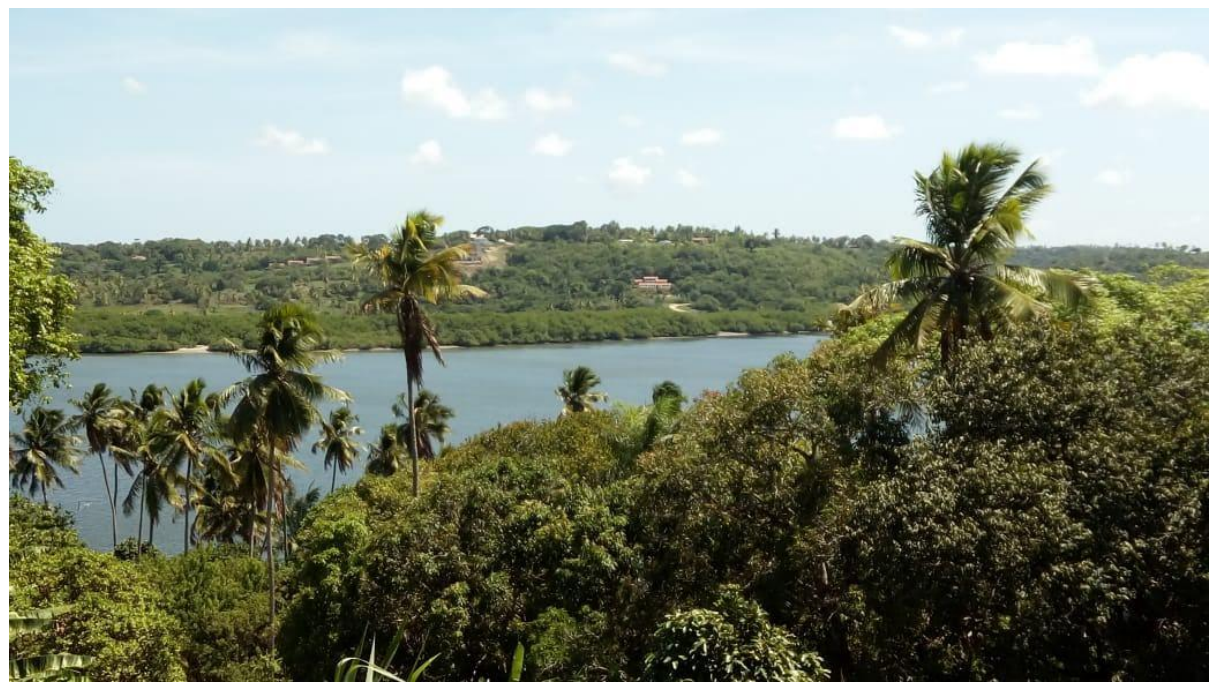

Fonte: Fonte: Acervo pessoal, 2019.

Em relação ao patrimônio cultural que envolve o sítio estudado, ele é tombado em nível estadual pela FUNDARPE e faz parte do conjunto histórico-arquitetônico do povoado o Forte de Santa Cruz, conhecido como Forte Orange, tombado em nível federal pelo Instituto do Patrimônio Histórico e Artístico Nacional (IPHAN) - Processo no 101/1938. Além disso, desde 1970, a Igreja de Nossa Senhora da Conceição (figura 4), ponto focal do povoado, encontra-se em processo de Tombamento pelo IPHAN - Processo no 831/1970. Ressaltando assim, sua importância histórico-cultural em escala nacional.

Figura 4: Patrimônio Cultural do povoado de Vila Velha

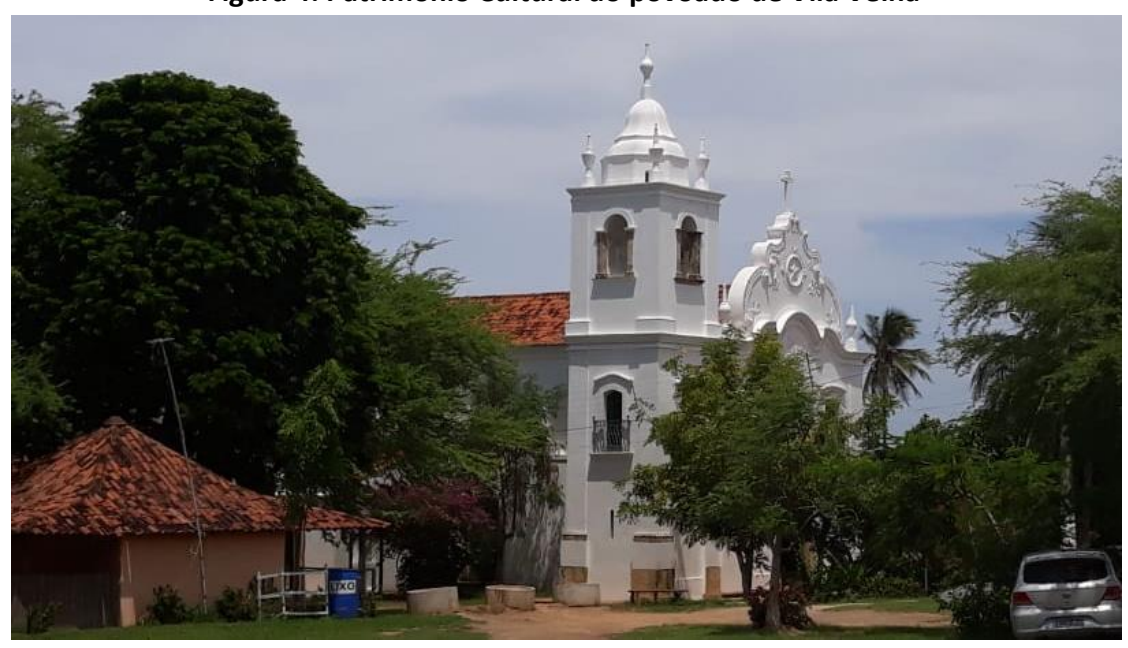

Fonte: Fonte: Acervo pessoal, 2019. 


\section{ANAP \\ Brasil \\ ISSN 1984-3240 v. 12, n. 25}

\section{REVISTA CIENTÍFICA 2019}

A Igreja é um remanescente da paisagem tradicional local de grande valor histórico que vem sofrendo alterações em sua estrutura arquitetônica com sobreposição de diversos períodos históricos, e no ambiente entorno com suas edificações e a relação com a natureza circundante. Hoje está caracterizada como um assentamento urbano com infraestrutura física básica deficitária e falta de recursos para sua manutenção, expressando uma paisagem urbana degradada com graves perdas da integridade e autenticidade desse valioso patrimônio cultural/natural, (figura 5).

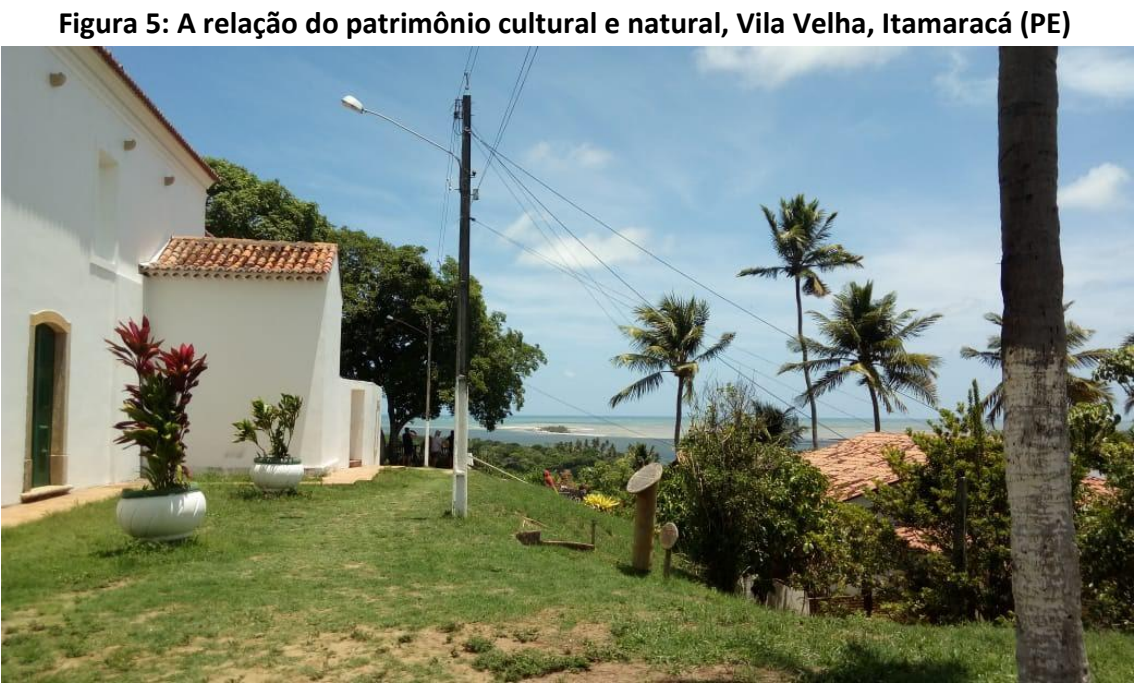

Fonte: Acervo pessoal, 2019.

O conjunto de Vila Velha possui um significado histórico bastante peculiar por ser um dos primeiros núcleos edificados do Brasil Colônia, cujo processo de formação diversificado remonta um período histórico muito importante para o Brasil. Os franceses conheciam as terras brasileiras desde 1503, quando sua primeira grande expedição aportou em terras brasileiras com a intenção de fundar uma colônia. Em meados de 1516-1519, foi enviada uma expedição de Cristóvão Jaques, com o objetivo inteiramente militar. Em sua chegada, Jaques dá início um combate aos franceses para exterminar a pirataria da madeira do pau-brasil. A Ilha de Itamaracá é um referencial histórico de extrema importância para a implantação da colônia portuguesa no Brasil, pois foi um dos primeiros pontos onde foram estabelecidas as feitorias, que serviram de apoio para o povoamento e instalações das primeiras vilas (OLIVEIRA; SANTOS, 2014). Isso levou o povoado a possuir um sítio arqueológico rico, com diferentes processos construtivos e culturais em que ainda nos dias atuais são descobertos novos canteiros de escavação de testemunhos históricos, descortinando as parcelas de um passado esquecido.

Todavia, atualmente, existem disfunções gerenciais e mau direcionamento no processo de gestão de sua conservação. Sem as devidas medidas de proteção as áreas com valor arqueológico, que se situam ao redor da Igreja de Nossa Senhora da Conceição estão sendo tratadas de forma inadequada. Em geral, visitantes do povoado estavam utilizando como 


\section{ANAP

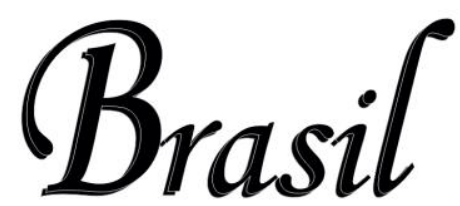 \\ ISSN 1984-3240 \\ V. 12, n. 25}

\section{REVISTA CIENTÍFICA 2019}

estacionamento o espaço onde se encontram prospecções de ossadas humanas, degradando o patrimônio arqueológico encontrado na Vila (FOLHA PE, 2018).

Outro aspecto bastante negligenciado no sítio são as ruínas das edificações históricas (figura 6) que outrora fizeram parte do povoado. Pelo fato de não serem reconhecidas por diversos atores gestores, desde os visitantes até os próprios agentes públicos dos órgãos de preservação, em vista da negligência quanto ao reconhecimento dos atributos patrimoniais no processo de salvaguarda, fazem-se necessárias medidas efetivas para sua conservação enquanto parte importante deste conjunto cultural/natural.

Figura 6: Ruína situada no povoado de Vila Velha

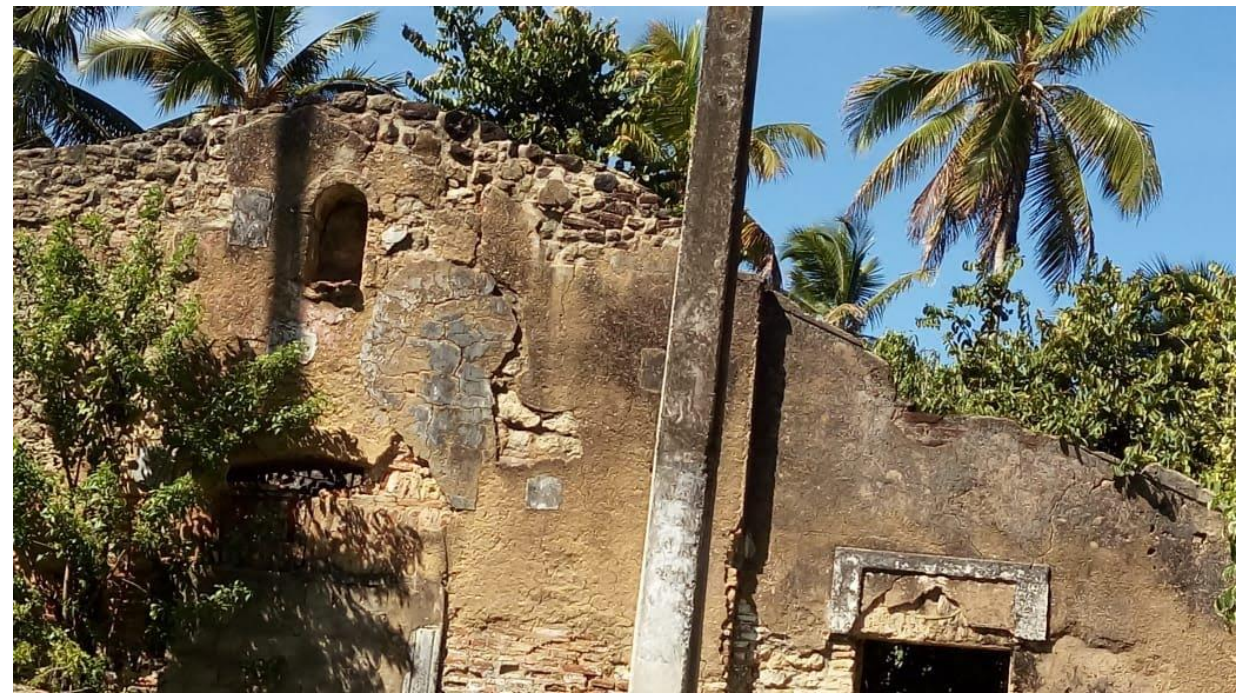

Fonte: Acervo pessoal, 2019.

Além disso, os elementos naturais da área não são levados em consideração de maneira integrada com o bem cultural ali presente, pois mesmo sendo uma área de preservação ambiental, não é considerada a inter-relação entre ecossistema natural com os elementos da cultura e história do local. Essa ligação entre o cultural e o natural é explicitamente constatada em poemas, cartas e descrições históricas anexadas ao processo de tombamento estadual. Verifica-se, a emergência de um plano de conservação integrada para a salvaguarda desse bem patrimonial.

Corroboram com este pensamento as afirmações dos especialistas na área da conservação quando inquiridos sobre uma gestão que integre os atributos culturais e naturais do bem. De acordo com os relatos levantados por meio de entrevistas semiestruturadas, Vila Velha reúne é um exemplar patrimonial onde estão reunidos os dois campos do patrimônio integrado. Esta relação é identificada no cotidiano do lugar, através da subsistência da população tradicional a partir dos produtos naturais locais, como as atividades pesqueiras e muitas delas ligada à culinária típica da localidade.

Atualmente, o local é reconhecido principalmente pelo seu aspecto natural, contudo relacionada aos valores culturais expressas por ela pelo sítio histórico de Vila Velha. Mesmo por se caracterizar como uma Área de Proteção Ambiental por seus fatores ecológicos e 


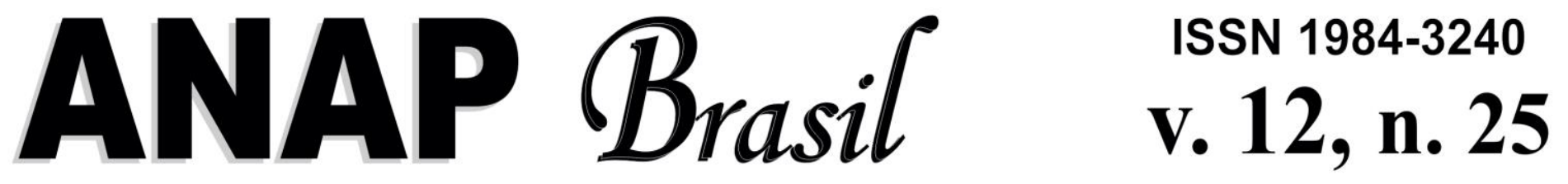

REVISTA CIENTÍFICA 2019

biológicos, o patrimônio natural do sítio é visto, tanto pela população residente quanto pelos visitantes, como paisagem no seu aspecto estético ou cênico. O marco referencial, no imaginário social, é a relação do mar com o verde, contudo integrado aos elementos históricos presentes nesse lugar, seja o sítio arqueológico com registro de uma época não mais encontrada, seja pelos elementos arquitetônicos que trazem ao tempo presente essa carga histórica da conformação urbana e social do nosso Brasil.

Mesmo com a falta de diretrizes e ações efetivas para a conservação deste sítio histórico, o seu estado de conservação não se encontra em pior situação devido à própria população que faz uma manutenção mínima da área. Por se tratar de uma comunidade local com um caráter tradicional, de vizinhança e por expressar o sentimento de pertencimento, a manutenção do lugar e o cuidado com os atributos patrimoniais são desenvolvidos pelos próprios moradores (figura 7). 0 reconhecimento do lugar, não apenas pelos elementos construídos, mas também a natureza, como algo inerente à sua história, faz com que a comunidade busque sua preservação, sendo este o principal fator que a fez permanecer ainda presente durante séculos.

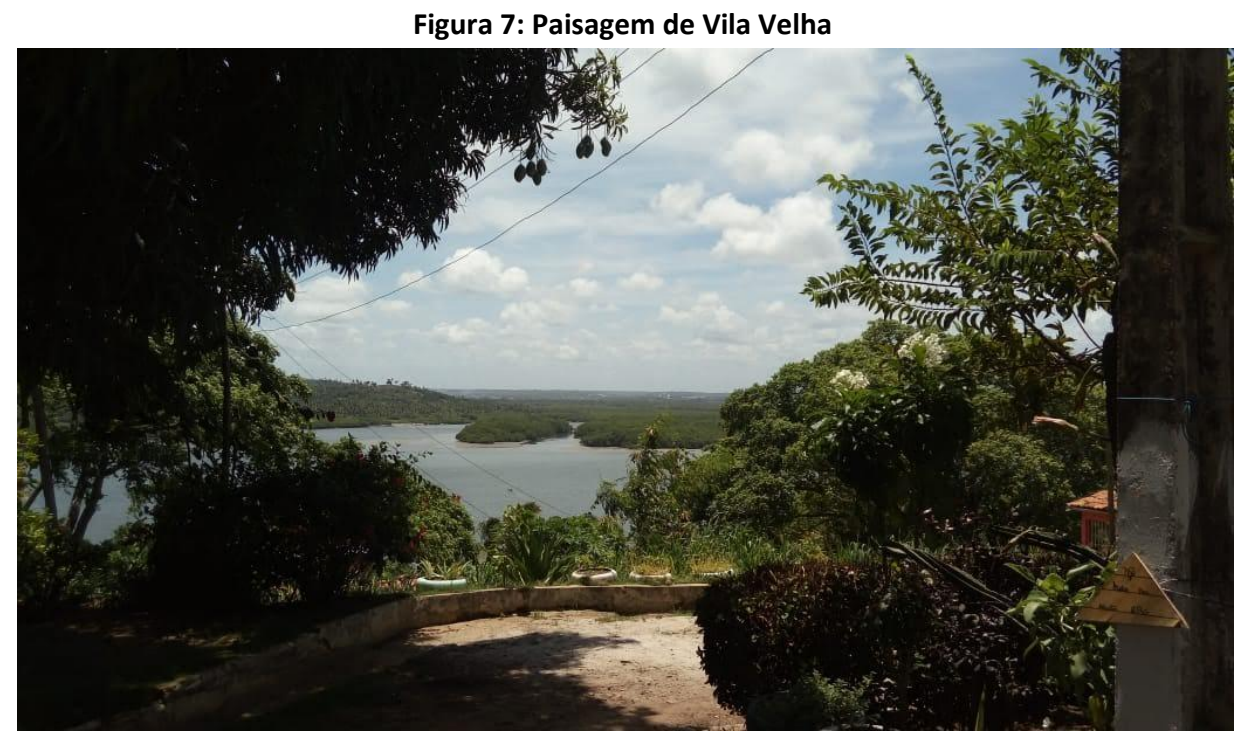

Fonte: Acervo pessoal, 2019.

\section{CONCLUSÃO}

Este artigo traz a discussão de que o patrimônio cultural/natural, presente no povoado de Vila Velha e seu entorno, vai além do cenário bucólico que representa o seu sítio histórico, mas agrega valores naturais muito importantes e também incorpora a materialização das vivências da sociedade naquele lugar. Essas duas dimensões, juntamente com os diversos outros atributos e valores são responsáveis por moldar a paisagem singular de Vila Velha.

Diante disso, a paisagem urbana e natural desse povoado, categorizada por seu caráter originalmente histórico, necessita de ações emergentes de salvaguarda frente ao risco de perda paulatina desse legado. Vale ressaltar que o tombamento do sítio não possui um 


\section{REVISTA CIENTÍFICA 2019}

apanhado detalhado dos bens que o compõem, somando-se ainda à alta de conservação de elementos significativos do sítio e, bem como o seu devido reconhecimento.

Diante da análise, ratifica-se que é necessária uma compreensão mais profunda e ampla dos atributos e valores conferidos a esse bem, objeto de interesse patrimonial excepcional, tanto na dimensão natural, quanto cultural. E para o reconhecimento da significância desse bem patrimonial, é imprescindível a identificação dos valores atribuídos pelos atores sociais diretamente envolvidos, para que se ratifiquem os elementos para os quais estarão voltadas as ações de conservação. E assim, levantam-se questionamentos sobre a forma de preservação do patrimônio nos dias de hoje, em face do tratamento distinto dado às suas dimensões naturais e culturais, como se não houvesse nenhuma relação entre si. Conclui-se que não se pode compreender um patrimônio desse tipo como sendo constituído por elementos isolados, porém como uma paisagem única, permeada de inter-relações entre as partes. Isso é o que pode garantir a preservação dos atributos os valores conferidos e, consequentemente, sua significância patrimonial enquanto bem único, ou uma totalidade.

Os resultados encontrados e os questionamentos levantados podem contribuir no processo formal de reconhecimento de Vila Velha como um bem patrimonial cultural e natural, e ainda servir como embasamento conceitual e metodológico para a construção de instrumentos de gestão da conservação integrada do patrimônio. E por meio desse percurso, revelar a importância do processo de identificação patrimonial e os riscos que uma má identificação e proteção dos bens podem trazer para sua proteção e salvaguarda.

\section{REFERÊNCIAS BIBLIOGRÁFICAS}

AB'SÁBER, Aziz Nacib. Os Domínios de Natureza no Brasil: potencialidades paisagísticas. São Paulo: Ateliê Editorial, 2003.

BERQUE, Augustin. Território e Pessoa: a identidade humana. Desigualdade \& Diversidade: Revista de Ciências Sociais da PUC-Rio, Rio de Janeiro, n. 6, p.11-24, 25 ago. 2010. Semestral.

CARTA EUROPEIA DA PAISAGEM. Convenção Europeia da Paisagem. Conselho da Europa (Florença), 2000.

FOLHA PE. Ossadas e objetos históricos surgem sob a terra no entorno de igreja em Itamaracá. Ilhade Itamaracá, p. 1-1. 05 dez. 2018. Disponível em:

<https://www.folhape.com.br/noticias/noticias/cotidiano/2018/12/05/NWS,89595,70,449,NOTICIAS,2190OSSADAS-OBJETOS-HISTORICOS-SURGEM-SOB-TERRA-ENTORNO-IGREJA-ITAMARACA.aspx>Acesso em: 30 mar. 2019.

GOOGLE MAPS, 2019

IUCN (Austrália). Australian Natural Heritage Charter: for theconservationofplacesof natural heritagesignificance. 2. ed., 2002.

OLIVEIRA, Ana Lúcia do Nascimento; SANTOS, Josué Lopes dos. A organização da defesa na ilha de Itamaracá no período colonial: uma contribuição para história do litoral de pernambuco. Lepaarq, Pelotas, v. 21, n. 11, p.2-11, 15 mar. 2014. 
